\title{
ABORTAMENTO ENTRE MULHERES VÍTIMAS DE VIOLÊNCIA SEXUAL: CONFLITOS E DESAFIOS
}

\author{
ABORTION AMONG WOMEN VICTIM OF SEXUAL VIOLENCE: CONFLICTS AND CHALLENGES
}

\section{Maiky Carneiro da Silva Prata ${ }^{a^{*}}$, Renata Sanzovo Pires de Campos ${ }^{b^{*}}$, Laila Batata Lopes Nunes de Souza ${ }^{*}$, Gustavo Leme Fernandes ${ }^{\mathrm{d}^{*}}$, Lúcia de Fátima Cahino da Costa Hime ${ }^{\mathrm{e}^{*}}$}

amaikycprata@gmail.com, brenatasanzovo@gmail.com, claila_batata@hotmail.com,

dglemefernandes@gmail.com, elfcchime@yahoo.com.br

*Universidade de Santo Amaro - São Paulo (SP), Brasil

Data de recebimento do artigo: 02/07/2015

Data de aceite do artigo: 17/09/2015

\section{RESUMO}

O aborto é frequentemente associado a experiências de coerção sexual no Brasil. Objetivo: Refletir sobre os enfrentamentos relacionados ao aborto entre mulheres vítimas de violência sexual sob o ponto de vista da mulher, do profissional de saúde e da legislaçáo vigente no Brasil, através do referencial teórico da vulnerabilidade. Métodos: Foi feita uma revisão narrativa/crítica da literatura (2004-2014) através das bases de dados MEDLINE via PubMed e LILACS, com os descritores "gênero", "vulnerabilidade", "mulheres", "aborto induzido" e "violência sexual". Desenvolvimento: Questôes referentes às desigualdades de gênero favorecem ações de violência sexual contra mulheres. Embora existam leis que garantam o direito do aborto à mulher violentada, ainda há uma lacuna entre a lei e sua aplicaçấo. Os princípios morais e religiosos incorporados na educaçáo brasileira favorecem o desrespeito, pelo profissional de saúde, do direito da mulher violentada optar pelo aborto. A carência na formaçáo dos profissionais de saúde, quanto ao conhecimento de protocolos de assistência à mulher violentada, implica dificuldades de percepção do evento violento como de saúde pública. Reconhecer a violência como um agravo de saúde é desafiador e envolve a necessidade de incorporação de novos hábitos profissionais. Conclusáo: Este estudo contribuiu para a compreensão dos conflitos entre mulheres vítimas de violência sexual e profissionais que diretamente trabalham com o aborto no Brasil, favorecendo ações de saúde de capacitação, atualização e treinamento para garantir o direito reprodutivo feminino com segurança.

Palavras-chave: Gênero e saúde; vulnerabilidade em saúde; mulheres; aborto induzido e violência sexual.

\section{ABSTRACT}

Abortion is often associated with sexual coercion in Brazil. Objective: To reflect on abortion among women victims of sexual violence from the point of view of women, health professionals and the current legislation in Brazil. Methods: A narrative review (2004-2014) through MEDLINE and LILACS data bases via PubMed. Descriptors: "gender", "vulnerability", "women", "induced abortion" and "sexual violence". Development: The inequality of gender favors violence against women. Although we have in the country laws guaranteeing the right of sexually abused women to abort, there is still a gap between the law and its application. Moral and religious principles incorporated into the Brazilian education favors disrespect of woman rights even by health professionals. The lack of knowledge about this topic in the health professionals' background as well as about protocols of sex offenses against woman implies difficulty to treat this fact as a public health problem. To recognize women violence as a public health problem is a challenge that involves the incorporation of new professional habits. Conclusion: This study contributed to understand the conflicts between women victims of sexual violence and professionals that work directly with abortion in Brazil, promoting health equity training and women's reproductive rights.

Keywords: Gender and health; health vulnerability; women; induced abortion and sexual violence. 


\section{Introdução}

A violência sexual contra mulheres e o aborto como consequência da gravidez indesejada são situaçóes intimamente relacionadas que causam impactos não apenas à mulher, mas a toda sociedade ${ }^{1}$.

Tanto a violência sexual quanto o aborto são eventos de grande relevância para a saúde pública e, ao serem tratados conjuntamente repercutem em implicaçóes éticas e legais de grande magnitude, nas quais se evidenciam questôes referentes à garantia dos direitos sexuais e reprodutivos da mulher, além de questóes relacionadas à desigualdade de gêneros ${ }^{2,3}$.

Conferências internacionais na década de 1990 (Cairo 94 e Beijin 95), reforçaram a importância do impacto da violência sexual na vida da mulher e propuseram novas discussões sobre a temática, que repercutem até os dias atuais,, entre governantes de todo o mundo ${ }^{1}$.

Um estudo publicado pelo ministério da saúde em 2008 revelou que a violência sexual é um agravo que atinge mulheres de todas as classes sociais, religióes e culturas, indistintamente, uma vez que o estupro ainda é um evento altamente frequente em todos os continentes do planeta. Homens ainda mantêm um pensamento de dominaçáo em relaçáo às mulheres, determinando uma relação desigual na expressão da sexualidade que favorece açóes de violência de homens contra mulheres ${ }^{4}$.Há evidências de que mais da metade dos casos de violência sexual ocorrem no período reprodutivo da mulher, sendo verificadas taxas de gravidez que oscilam entre 1 e $7 \%$ entre mulheres violentadas. $\mathrm{O}$ aborto mostra-se como prática frequentemente associada a experiências de coerção sexual, e figura entre as quatro principais causas de mortalidade materna no Brasil ${ }^{5,6,7}$.

A imposição de medidas restritivas no manejo das questóes referentes à violência sexual e ao aborto apenas aumenta o abandono e a desvalorização dos direitos femininos ${ }^{8}$. Além disso, outros problemas sociais são aventados, inclusive a respeito do posicionamento dos profissionais de saúde na participação em atendimento a mulheres vítimas de violência sexual que, por se sentirem desamparadas pelo Estado, desinformadas e até envergonhadas, optam pela realização do aborto clandestino?.

Esse procedimento resulta em diversos conflitos, sendo o principal a segregação social, pois uma mulher com alto poder aquisitivo poderá se informar, irá a outro país ou até mesmo procurará uma clínica clandestina segura para realizar o aborto, inclusive livre do risco de ser penalizada pela interrupção da gestação. Contudo, uma mulher carente se submeterá a condiçốes mais adversas para interromper a gravidez, colocando sua vida em risco e se submetendo a mutilaçóes ${ }^{10,11}$.
Nos últimos anos, inclusive no Brasil, leis em favor da mulher e dos seus direitos sexuais e reprodutivos têm ganhado espaço nas decisóes políticas. Mesmo assim, muitos casos de violência e aborto ainda são registrados no país. Em 2010 foi estimado que 1/5 das mulheres em idade reprodutiva e moradoras de área urbana (18 a 39 anos, totalizando, aproximadamente 30 milhóes) no Brasil já realizaram aborto. Em outra norma técnica publicada pelo Ministério da Saúde em 2011, foram estimados um milhão de abortos por ano ${ }^{2,12}$.

Embora exista uma preocupação governamental em respeitar os direitos femininos, não se verifica verdadeiro impacto no processo de tomada de decisão e mudanças de comportamento dos agressores. Portanto, ainda há muito que se investigar para que o aborto entre mulheres vítimas de violência sexual seja enfrentado como um fenômeno que necessita de redefinição política, para que se compreenda essa temática como problema de saúde pública e não como um ato de infração moral de mulheres levianas, sendo essa a motivação para a realização deste estudo.

\section{Objetivos}

Refletir sobre os enfrentamentos relacionados ao aborto entre mulheres vítimas de violência sexual sob o ponto de vista da mulher, do profissional de saúde e da legislaçáo vigente no Brasil, com o olhar do referencial teórico da vulnerabilidade.

\section{Metodologia}

A proposta deste estudo foi realizar uma revisão narrativa/crítica da literatura (2004-2014) através das bases de dados MEDLINE (Medical Literatura Analysis and Retrieval System Online) via PubMed e LILACS (Literatura Latino-Americana e do Carie em Ciências da Saúde), tendo como referência de pesquisa os termos "gênero", "vulnerabilidade", "mulheres", "aborto induzido" e "violência sexual". Trata-se de uma revisão narrativa que apoia sua técnica em um texto qualitativo que fornece sínteses narrativas, compreendendo informaçóes publicadas anteriormente. A técnica de revisão narrativa abrange um maior conjunto de questóes relacionadas ao tópico específico, constituindo um instrumento útil com informaçóes em formato legível, dando alargada perspectiva ao assunto em revisão. Além disso, o modelo de revisão narrativa permite reunir pesquisas com métodos diferentes, sendo seu produto final o estado atual de conhecimento. Dados secundários publicados em órgãos de pesquisa vinculados ao Ministério da Saúde do Governo Federal, da Organização Mundial 
de Saúde (OMS) e a legislação vigente sobre a temática também foram consultados. Como referencial teórico utilizamos o conceito de vulnerabilidade com raízes nos direitos humanos, por discutir não apenas a esfera individual de risco, mas também a coletiva e os desdobramentos da dimensão programática e social.

\section{Desenvolvimento}

\section{Direitos reprodutivos e violência sexual: uma questão de gênero}

Historicamente, homens são colocados em posição de privilégio de direitos sobre as mulheres, sendo a violência sexual contra a mulher uma questão de gênero, consequente de um pensamento socialmente construído em que a vontade da mulher é subjugada à decisão masculina $^{13,14}$.

Nesse contexto, à luz do referencial da vulnerabilidade, especificamente da dimensão individual, a filosofia mostra de variadas formas os mecanismos de construçáo do pensamento de hegemonia masculina. Na mitologia grega, por exemplo, contava-se que, pelo fato de Pandora ter aberto a caixa de todos os males do mundo, as mulheres seriam as responsáveis por todos os tipos de mazelas que afligem a humanidade ${ }^{4}$.

$\mathrm{Na}$ religião também são verificadas justificativas para a legitimação de condutas próprias de cada sexo. No relato judaico-cristão, sendo Eva a responsável pela expulsão do Paraíso, a desigualdade é reforçada. Assim como na história da Virgem Maria, que pela supervalorizaçáo do seu exemplo de humildade, obediência e doaçấo pode refletir para a mulher uma posição de subordinação em relação ao homem ${ }^{4}$.

Não somente as mitologias e religióes apresentam a origem das desigualdades de gênero, como também a própria ciência, que, no estabelecimento das sociedades modernas, excluiu as mulheres de seus direitos políticos, como o poder de voto, e impôs a elas a responsabilidade integral pela maternidade ${ }^{13,15}$. Assim, observa-se que o conceito de gênero de caráter desigual como conhecido atualmente teve origem multifatorial, fatores que parecem legitimar o sentimento de propriedade que os homens apresentam sobre as mulheres.

Esse sentimento de posse repercute inclusive sobre a decisão da mulher em relação ao seu corpo, sua sexualidade e reprodução. Na zona rural da Tanzânia, 17\% das mulheres relataram terem tido sua primeira experiência sexual forçada, e dado semelhante é encontrado entre $24 \%$ das mulheres no Peru e 30\% em Bangladesh, na Índia ${ }^{5}$.
Em estudo realizado com mulheres moradoras de abrigos nos Estados Unidos, vítimas de violência, 53 mulheres relataram que seus companheiros a obrigavam a ter relaçóes sexuais forçadas e desprotegidas, sem uso de preservativos ou qualquer outro método contraceptivo. Uma vez grávidas, os parceiros masculinos passavam a ameaçá-las para influenciar o destino da gestação, confirmando o pensamento de dominaçáo que impacta a dimensão individual da vulnerabilidade feminina no que diz respeito a situações de violência sexual ${ }^{16}$.

A violência inerente à condição do gênero feminino se manifesta muito nitidamente quando se observa que entre $85 \%$ e $90 \%$ dos crimes de violência sexual são praticados contra mulheres, sendo a maioria dos casos praticados por parceiros íntimos. Essa situação é um grande desafio no manejo do cuidado com mulheres violentadas ${ }^{17}$.

Mulheres vítimas de parceiros desconhecidos que chegam aos serviços de saúde, solicitando socorro e medidas de interrupção da gestação, são aceitas e acolhidas de maneira diferente daquelas que pedem socorro por terem sido violentadas por parceiros íntimos, as quais são criticadas, pois o pensamento social acredita que a mulher, por ter uma relação conjugal, tem obrigaçóes sexuais com seu parceiro, e satisfazê-lo sexualmente mesmo contra a sua vontade faz parte das tarefas conjugais $^{18,19}$.

O combate da violência de gênero realmente é um desafio. Em levantamento realizado pelo centro internacional de pesquisas sobre a mulher, publicado em 2010, e na análise de dados secundários de pesquisas realizadas na América Latina e Caribe também foi apontado que a maioria dos casos de violência sexual registrados é realizada por parceiros íntimos e, mesmo entre os casos de violência sexual realizada por parceiros não íntimos, menos de $30 \%$ são por homens desconhecidos, sendo grande parte feita por amigos, professores, vizinhos, familiares e líderes religiosos ${ }^{18}$.

Há um conjunto de normas modeladoras do comportamento de homens e mulheres que definem os papéis sociais de cada gênero muito antes do nascimento, sendo a vulnerabilidade individual feminina inerente a sua posição de mulher na sociedade ${ }^{14}$.

Quando considerada a dimensão social da vulnerabilidade, que abrange os aspectos culturais e econômicos envolvidos nas oportunidades de acesso à informaçáo, educação e aos serviços de saúde ${ }^{20}$, fica evidente a complexidade da problemática, pois, sendo a informação o principal meio sobre contracepção, que é a ação preponderante para mudar a história natural da gravidez indesejada, questiona-se se a análise da vulnerabilidade individual isolada é suficiente para se conquistarem respostas. Sugere-se que há outros determinantes sociais que levam mulheres, por exemplo, de 
alta escolaridade a provocarem aborto, mesmo quando possuem informação.

A influência cultural dessa realidade pode ser observada entre tribos de países africanos, como na República do Congo, onde o estupro sistemático é usado como arma de guerra diante dos conflitos entre os povos congoleses, resultando em gravidez indesejada, grande incidência de aborto inseguro e mortalidade materna ${ }^{8}$.

A vulnerabilidade social se reproduz nos aspectos referentes à oportunidade de trabalho e salário fixo, que podem ter mais impacto no exercício dos direitos reprodutivos do que nos efeitos diretos que uma maior escolaridade poderia oferecer ${ }^{6}$. Assim, embora o aborto seja mais frequente entre as mulheres de baixa escolaridade, esta é uma variável que deve ser analisada com cautela.

A condição de exclusão social afeta diretamente a decisão sobre o aborto e o desfecho da prática. Foi evidenciado entre refugiadas libanesas que $39,5 \%$ das mulheres que se encontravam grávidas enfrentaram problemas para seguir com a gestação, e destas $36,8 \%$ sofreram graves complicaçóes associadas ao aborto e parto, por causa de situaçóes de abandono e exclusão ${ }^{21}$.

Sob o ponto de vista da dimensão programática, que se destina às proposiçóes de cumprimento, realização de políticas de continuidade, programas e serviços voltados para resoluçáo do problema, as questóes relativas aos direitos sexuais e reprodutivos da mulher ainda necessitam sair do plano das leis. Embora desde 1940 o código penal brasileiro reconheça como legal o aborto em casos decorrentes de violência sexual, apenas em 1989 se instituiu o primeiro serviço no Brasil de atendimento a vítimas de abuso sexual, e mesmo depois de quase 25 anos, ainda hoje se verificam ações em que o pensamento pessoal de gestores ou de profissionais de saúde, pautados em valores morais ou religiosos, impede o livre exercício dos direitos das mulheres ${ }^{22}$.

Assim, para que os direitos sejam de fato garantidos como responsabilidade do Estado, medidas de mudança de comportamento devem ser estabelecidas. O despreparo dos profissionais de saúde em lidar com questóes relacionadas a medidas de interrupção induzida da gestação, violência sexual e relaçóes de gênero influi negativamente na preservação do direito da mulher, inclusive no atendimento de casos de abortamento previstos em lei ${ }^{23}$.

A falta de preparo e de domínio dos aspectos que tangem às questôes referentes à violência sexual e aborto é agravada, uma vez que o tema não é comum na formação de profissionais de saúde, mesmo entre aqueles que trabalham em serviços de atendimento a mulheres violentadas. $^{3}$

Portanto, em vista dos fatos observados, ficam evidentes os desafios a serem superados nas três dimensões da vulnerabilidade para que as políticas públicas de respeito aos direitos sexuais e reprodutivos da mulher sejam de fato executadas.

Histórico da legislação em defesa dos direitos sexuais e reprodutivos da mulher no Brasil

Desde 1940 o código penal brasileiro contempla determinaçóes que regulamentam o aborto legal no país. Segundo o artigo 128 do código penal brasileiro, o aborto é direito da mulher quando a gestação coloca sua vida em risco e quando é decorrente de estupro. No entanto, há uma lacuna temporal entre a promulgação da lei e a elaboração de estratégias efetivas de resolução do problema da violência sexual e aborto no país. Apenas na década de 1980 tivemos as primeiras medidas do Estado para garantir os direitos da mulher, já previstos em lei há mais de 30 anos $^{24}$.

As iniciativas do Estado em discutir as questôes relacionadas à garantia dos direitos da mulher foram fomentadas pelas campanhas originadas dos movimentos feministas no Brasil. Passado o período das décadas de 1960 e 1970, nas quais o Brasil sofreu grande crescimento econômico decorrente do surgimento de indústrias e principalmente do fim da ditadura na década de 1980, a mulher passou a ter outra posição na sociedade, com novas oportunidades de inserção no mercado de trabalho e no sistema educacional, dando força aos movimentos feministas. Assim, as questóes relativas aos direitos sexuais e reprodutivos da mulher passaram a integrar as estratégias de governo no país ${ }^{4}$.

Em 1989 surgiu na cidade de São Paulo o primeiro serviço de atendimento a mulheres vítimas de violência sexual e assistência ao aborto legal, que por anos foi o único serviço no Brasil. Em 1994, também no município de São Paulo, foi instituído o segundo serviço ${ }^{1,2}$.

$\mathrm{Na}$ década de 1990, com a participação do Brasil na Conferência Internacional de Cairo, que tratava de assuntos sobre população e desenvolvimento, e na IV Conferência Internacional sobre as mulheres em Pequim, houve fortalecimento dos movimentos feministas e maior visibilidade das questóes da mulher no país, inclusive depois do apoio da Federação Brasileira de Ginecologia e Obstetrícia (Febrasgo), o movimento ganhou força com os representantes do governo, resultando, em 1997, na aprovação pelo Conselho Nacional de Saúde da resolução no 258 , que solicitava a regularização e normatização do atendimento no Sistema Único de Saúde (SUS) dos casos de aborto legal. Essa resolução foi introduzida no ano seguinte, quando o Ministério da Saúde (MS) editou a Norma Técnica para Prevenção e Tratamento dos Agravos Resultantes da Violência Sexual contra Mulheres e Adolescentes ${ }^{25}$.

A Norma Técnica (NT), embora não fosse de adoção obrigatória, incentivou muitas secretarias de saúde, resultando em expansão dos serviços de interrupção da gravidez decorrentes de violência sexual. No entanto, as 
estratégias de intervenção efetivas em defesa da mulher ainda se mostraram morosas, e apenas em 2005 o MS lançou outra NT que contemplava uma normatização com recomendaçóes de condutas aos serviços de saúde de manejo de aborto humanizado no país.

Em 2006, com a aprovação da Lei no 11.340 (Maria da Penha), que trata da criação de mecanismos para coibir a violência doméstica e contra a mulher, a questão da violência sexual também é abordada, e no capítulo II $\$ 3^{\circ}$ há proposições acerca do atendimento de emergência a mulheres violentadas sexualmente, no qual constam medidas de contracepção de emergência e profilaxia das Doenças Sexualmente Transmissíveis (DST) e Síndrome da Imunodeficiência Adquirida (AIDS).

No entanto, mesmo passados mais de dez anos da elaboração da primeira NT, e mais de seis anos da promulgação da Lei Maria da Penha, em 2012, o estudo realizado por Drezzet divulgou que entre mais de 700 municípios brasileiros, mais de $40 \%$ das secretarias municipais de saúde não sabiam responder se ofereciam serviço de atendimento ao aborto de mulheres vítimas de estupro. Destes munícipios, 30\% declaram que não tinham nenhum tipo de regulamentação para o atendimento de mulheres vítimas de violência sexual, independentemente das consequências para a mulher ${ }^{26,27}$.

Assim, é questionado se essa morosidade de açóes, de alguma forma, está relacionada ao conservadorismo moral e religioso, ou ainda à manutenção do pensamento de supremacia masculina sobre as mulheres presenciado no Brasil.

Embora o país ainda apresente uma das legislaçôes mais restritivas do mundo, vêm ocorrendo avanços significativos a respeito dos direitos sexuais e reprodutivos das mulheres. Em abril de 2012, o Supremo Tribunal Federal (STF) autorizou o aborto em casos de anencefalia, sacramentando uma prática que ocorria no Brasil há mais de 20 anos, mediante alvarás judiciários. Essa ação do STF, que teve critérios definidos pelo Conselho Federal de Medicina (CFM) (Resolução CFM n ${ }^{\circ}$ 1989/2012), ainda repercute de forma polêmica entre as correntes mais conservadoras do congresso nacional, mas, por ser uma medida que não obriga a mãe compulsoriamente a realizar o aborto e sim lhe dá o direito de optar por realizá-lo, é um exemplo de valorização do direito reprodutivo da mulher e de domínio do seu próprio corpo. Outra polêmica ainda travada é pela falta de NTs para orientar condutas na prática de aborto em casos de anencefalia, mas acredita-se que muito em breve o MS divulgará medidas para que os profissionais de saúde mantenham o mesmo padrão nas condutas ${ }^{28}$.

Ainda respondendo às pressões da sociedade civil, dos movimentos feministas e demais órgãos que lutam pela valorização dos direitos da mulher no Brasil, em 2013 foi sancionada a Lei $\mathrm{n}^{\mathrm{o}} 12.845$ de $1^{\circ}$ de agosto, que dispóe sobre o atendimento obrigatório e integral, pelos serviços integrados ao SUS, de pessoas em situação de violência sexual. A lei, na verdade, valida aquilo já estabelecido em portaria pelo MS, na política de atendimento humanizado a vítimas de violência sexual, e ratifica, entre outros aspectos, a importância da contracepção de emergência para casos de estupro. Já é sabido que a prática, além de valorizar os direitos reprodutivos da mulher, reduz o número de abortos legais no país.

Desde 2008, ano em que o número de serviços do SUS voltados à atenção às vítimas de violência sexual quase triplicaram, o número de abortos legais no país reduziram em mais de 50\%. Ou seja, as estatísticas mostram que instituir políticas que garantem os direitos sexuais e reprodutivos das mulheres traz repercussões positivas não apenas individuais, mas para toda a sociedade.

Conflitos vivenciados por profissionais de saúde na assistência de mulheres vítimas de violência sexual

Embora tenha se avançado bastante com relação às leis que regulamentam os direitos sexuais e reprodutivos das mulheres, ainda se verifica um distanciamento entre legislação e execução das medidas de proteção por parte de profissionais e gestores de saúde. Nesse sentido, há um desafio em delimitar as causas que alimentam a lacuna entre o dever do Estado e a garantia efetiva de direitos $^{9,19}$.

Não apenas os princípios moralistas e religiosos dos profissionais de saúde impedem o reconhecimento e a legitimidade das questóes decorrentes da violência sexual e do aborto, como também a dificuldade de perceber o "evento violência" como um problema de saúde pública ${ }^{3}$.

Historicamente, doenças são caracterizadas por alteraçóes anatomopatológicas, que apresentam agente etiológico isolado e reconhecido, portanto, reconhecer a violência por si só como um agravo de saúde envolve a necessidade de incorporação de novos hábitos na prática profissional. Talvez a dificuldade relativa à mudança de hábitos tenha contribuído para que ainda hoje, em muitos serviços de saúde, a violência contra a mulher seja negligenciada por médicos, enfermeiros e demais profissionais. Há evidências desse discurso biomédico, por exemplo, quando é verificado que mulheres que chegam aos serviços de saúde com mutilaçôes e demais consequências aparentes da violência sensibilizam mais os profissionais do que aquelas que relatam apenas abalos emocionais, sem prova física da violência ${ }^{2,25}$.

A falta de conhecimento dos profissionais de saúde, resultante da deficiente maneira que questôes referentes ao aborto são tratadas em cursos de formação, seja na graduação ou em atualizaçóes pelos serviços de saúde, concentra, de certa maneira, outra causa do descumprimento da lei. Muitos profissionais de saúde se sentem 
desamparados no momento em que precisam decidir, por exemplo, se participam de uma atividade de aborto, mesmo quando prevista na lei. Há certo medo de posteriormente serem penalizados e julgados pela prática do aborto, desencadeando uma cadeia de barreiras para que a mulher tenha seu direito garantido ${ }^{25}$.

O moralismo, o pensamento cristão e o conservadorismo social certamente também fazem parte dos entraves enfrentados pelos profissionais de saúde na decisáo de auxiliarem no aborto. Muitos médicos e enfermeiros foram criados com princípios de que o aborto é criminoso e abominável; então, se desvincularem desse raciocínio e de julgamentos e preconceitos é um constante desafio $^{22}$.

Nesse contexto, em que a problemática do aborto se apresenta de maneira complexa e multifatorial, também deve ser considerada a ansiedade gerada no profissional de saúde ao lidar com questóes tão conflitantes. Esse agente lida com uma demanda peculiar de necessidades; a violência, o desespero, o abandono e demais mazelas certamente têm impacto em suas vidas, sendo necessários informação, treinamento e apoio para que consiga desempenhar seu trabalho de maneira consciente e eficaz $^{19,22}$.

Assim, para que cada vez mais ocorra diminuição da lacuna que existe entre lei e execução da lei, os serviços de saúde e gestores devem investir em capacitaçáo, atualização e treinamento de profissionais, para que a violência sexual e o aborto sejam reconhecidos cada vez mais como problemas de saúde pública, e que uma mulher violentada se sinta segura e respaldada ao procurar um serviço de emergência; para que essa mulher não seja marginalizada, culpada e criticada por ter sido vítima de violência sexual, mas acolhida e receba todas as medidas de apoio preconizadas internacionalmente por profissionais conscientes e seguros de suas condutas.

\section{Conclusão}

As evidências mostram que a violência sexual e o aborto como consequência de gravidez indesejada são problemas de saúde pública, e a valorização desses agravos por parte do Estado é um compromisso da garantia ao acesso à saúde e respeito aos direitos humanos. Assim, o gerenciamento do Estado dessa temática é essencial para a elaboraçáo de programas de saúde reprodutiva que forneçam recursos em prol da proteçáo da mulher, podendo dar um desfecho mais favorável em situaçóes de violência sexual e aborto. O referencial teórico da vulnerabilidade favorece o reconhecimento dos fenômenos envolvidos nas açôes de violência contra a mulher e desrespeito dos seus direitos sexuais e reprodutivos. $\mathrm{O}$ fomento de políticas públicas, com estratégias voltadas à educação dos profissionais envolvidos no atendimento da mulher violentada, tanto no âmbito da saúde como da segurança pública, pode influenciar de forma positiva a realização de abortos mais seguros. Garantia de acesso ao trabalho remunerado e anticoncepçáo individualizada também são medidas que tornam as mulheres menos vulneráveis à violência sexual e ao consequente aborto inseguro.

\section{Referências}

1. Ministério da Saúde. Secretaria de Atenção à Saúde. Prevenção e tratamento dos agravos resultantes da violência sexual contra mulheres e adolescentes: norma técnica. Brasília (DF): 2012.

2. Ministério da Saúde. Secretaria de Ciência, tecnologia e insumos estratégicos. Aborto e Saúde pública no Brasil: 20 anos. Brasília (DF): 2009.

3. Drezett JP, Pedroso D. Aborto e violência sexual. Cienc Cult. 2012 Jul;64(2):35-8.

4. Puleo AH. Filosofia e gênero: da memória de passado ao projeto de futuro. In: Godinho, Tatau, Da Silveira, María Lúcia. Políticas públicas e igualdade de gênero, São Paulo, Cadernos da Coordenadoria Especial da Mulher. 2004;8:13-34.

5. Organização Mundial da Saúde. Prevenção da violência sexual e da violência pelo parceiro íntimo contra a mulher: ação e produção de evidência. Washington, D.C., 2010.

6. Adesse L, Monteiro MFG. Magnitude do aborto no Brasil: aspectos epidemiológicos e socioculturais. Revista de Saúde Sexual e Reprodutiva. 2007;66:10-5.

7. Ministério da Saúde. Secretaria de Vigilância em Saúde. Saúde Brasil 2011. Uma análise da situação de saúde e de evidencias selecionadas de impacto de açóes de vigilância em saúde. Capítulo 14: Mortalidade materna no Brasil: Principais causas de morte e tendências temporais no período de 1990 a 2010. Brasília (DF): 2012.

8. Kalonda JC. A violência sexual no Congo-Kinshasa: necessidade de descriminalizar o aborto. Rev Med Brux. 2012 Out;33(5):482-6.

9. Silva PC. Violência de gênero perpetrada por parceiro íntimo sob a ótica dos profissionais de saúde da emergência do Hospital Municipal Paulino Werneck. Rio de Janeiro, 2009. [Trabalho de Conclusão de Curso de Graduação] Rio de janeiro: Escola de Serviço Social, Universidade Federal do Rio de Janeiro; 2009.

10. Domingos SRF, Merighi MAB. O aborto como causa de mortalidade materna: um pensar para o cuidado de enfermagem. Esc Anna Nery Rev Enferm. 2010 Jan-Mar;14(1):177-81.

11. Ministério da Saúde. Secretaria de Atenção à Saúde. Atenção humanizada ao abortamento: norma técnica. Brasília (DF):2011. 
12. Diniz D, Medeiros M. Aborto no Brasil: uma pesquisa domiciliar com técnica de urna. Ciência \& Saúde Coletiva. 2010 Maio;15(1):959-66.

13. Pilecco FB, Knauth DR, Vigo A. Aborto e coerção sexual: o contexto de vulnerabilidade entre mulheres jovens. Cad Saúde Pública. 2011 Mar;27(3):427-39.

14. Prata MCS, Nichiata LYI, Takahashi RF, Bertolozzi MR. Vulnerabilidade de Mulheres à Aids: estudo da mortalidade segundo anos potenciais de vida perdidos. O Mundo da Saúde. 2009;33(4):440-48.

15. Ministério da Saúde. Secretaria Municipal da Saúde. Caderno de Violência Doméstica e Sexual Contra a Mulher. São Paulo: 2007.

16. Thiel BH, Rostovtseva DP, Khera S, Godhwani N. Birth control sabotage and forced sex: experiences reported by women in domestic violence shelters. Violence Against Women. 2010 Maio;16(5):601-12.

17. Schraiber LB, Oliveira APLD, Junior IF, Diniz S, Portella $\mathrm{AP}$, Ludermir $\mathrm{AB}$ et al. Prevalência da violência contra a mulher por parceiro íntimo em regióes do Brasil. Rev Saúde Pública. 2007 Out;41(5).

18. Contreras JM, Bott S, Guedes A, Dartnall E. Violência sexual na América Latina e no Caribe: uma análise de dados secundários. Iniciativa de Pesquisa sobre Violência Sexual; 2010.

19. Farias RS, Cavalcanti LF. Atuação diante das situaçóes de aborto legal na perspectiva dos profissionais de saúde do Hospital Municipal Fernando Magalhães. Ciênc saúde coletiva. 2012 Jul;17(7).
20. Almeida FN, Ayres JR. Riesgo: concepto básico de La epidemiologia. Salud colectiva. 2009 Set;5(3).

21. Masterson AR, Usta J, Gupta J, Ettinger AS. Assessment of reproductive health and violence against women among displaced Syrians in Lebanon. BMC Women's Health. 2014 Fev 20;14(1):25.

22. Henriques CV. Perfil clínico-epidemiológico das mulheres vítimas de violência atendidas no serviço de apoio à mulher [dissertação]. Recife: Instituto Materno-Infantil de Pernambuco; 2004.

23. Cacique DB, Junior PR, Osis MJMD. Opiniōes, conhecimento e atitudes de profissionais da saúde sobre o aborto induzido: uma revisão das pesquisas brasileiras publicadas entre 2001 e 2011. Saúde Soc. São Paulo. 2013;22(3):916-36.

24. Leocádio EMA. Aborto pós-estupro: uma trama (des)conhecida entre o direito e a política de assistência à saúde da mulher [dissertação]. Brasília: Universidade de Brasília; 2006.

25. Ministério da Saúde. Secretaria de Atenção à Saúde. Magnitude do aborto no Brasil. Brasília (DF); 2008.

26. Cecatti JG, Guerra GVQL, Souza MH, Menezes GMS. Aborto no Brasil: um enfoque demográfico. Rev Bras Ginecole Obstet. 2010;32(3):105-11.

27. Ministério da Saúde. Secretaria de Atenção à Saúde. Atenção humanizada ao abortamento. Brasília (DF); 2011.

28. Andrade TO. O aborto em caso de anencefalia. Âmbito Jurídico. 2012 jul. Disponível em: http://www.ambito-juridico.com.br/site/?n_link=revista_artigos_leitura\&artigo_ $\mathrm{id}=11742$. [acesso em: 20 out 2015].

\section{Como citar este artigo:}

Prata MCS, Campos RSP, Souza LBLN, Fernandes GL, Hime LFCF. Abortamento entre mulheres vítimas de violência sexual: conflitos e desafios. Rev. Aten. Saúde. 2015;13(46):106-12 